\title{
Formation Mechanism of the $\mathrm{Co}_{2} \mathrm{C}$ Nanoprisms studied with CoCe system in the Fischer-Tropsch to Olefins Reaction
}

Zhengjia Li ${ }^{a,}{ }^{*}$, Danmeng $\mathrm{Yu}^{a}{ }^{a}$, Linyan Yang ${ }^{a}$, Jie Cen ${ }^{a}$, Kang Xiao $^{b}$, Nan Yao ${ }^{a,}{ }^{*}$, Xiaonian $\mathrm{Li}^{\text {a }}$,

a Institute of Industrial Catalysis, College of Chemical Engineering, Zhejiang University of Technology, Hangzhou 310014, China

b School of Materials Science and Engineering, Nanjing University of Posts and Telecommunications, Nanjing 210024, China

\section{Corresponding Author}

*E-mail for Z. J. Li: lizhengjia@zjut.edu.cn

*E-mail for N. Yao: kenyao@zjut.edu.cn

*E-mail for X. N. Li: xnli@zjut.edu.cn

\section{Table of Contents}

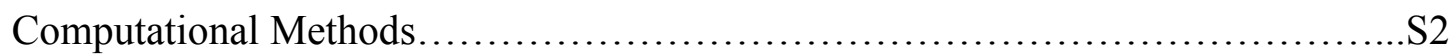

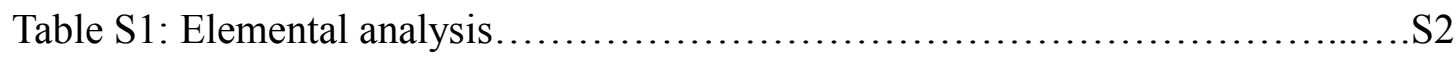

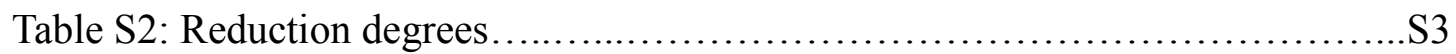

Table S3: Particle size......................................................... 3

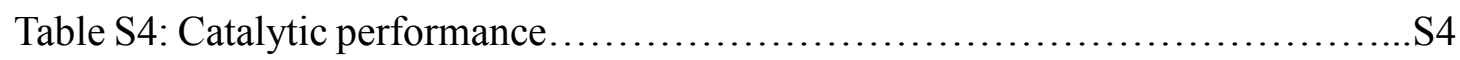

Figure S1: TEM images of the reduced catalysts................................. 5

Figure S2: Particle size distributions of the reduced catalysts...................S6

Figure S3: STEM-EDS images of the reduced catalysts........................... 7

Figure S4: Particle size distributions of the spent catalysts.......................S8

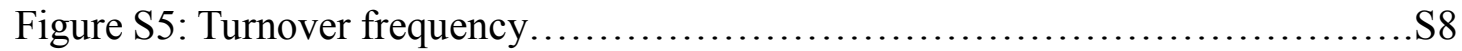

Figure S6: TEM images of the spent catalysts.................................. 9

Figure S7: HRTEM images of the intermediates............................. 10

Figure S8: HRTEM images of the intermediates.............................. 11

Figure S9: Sketch of the formation process.................................. 12

Figure S10: Side views of the $\mathrm{Co}_{2} \mathrm{C}$ surfaces................................. 12 


\section{Computational Methods}

The first principles density functional theory (DFT) calculations were performed using the Vienna ab initio Simulation Program (VASP) package. The projector-augmented wave (PAW) method was used at a plane-wave cutoff of $400 \mathrm{eV}$ to decouple the core from valence electrons. The Perdew-Burke-Ernzerhof (PBE) exchange-correlation functional was used throughout our calculations. The integration over the Brillouinzone integrations was performed with a $6 \times 6 \times 1$ Monkhorst-Pack k-point grid in case of $\mathrm{Ce}_{2} \mathrm{O}_{3} @ \mathrm{Co}_{2} \mathrm{C}$ interface and different $\mathrm{Co}_{2} \mathrm{C}$ surface structures. The size of the mesh was optimized to converge the absolute energy to $1 \times 10^{-5} \mathrm{eV}$ with a force convergence of $1 \times 10^{-4} \mathrm{eV} / \AA$. Methfessel-Paxton smearing with a width of $0.2 \mathrm{eV}$ was applied for the $\mathrm{Ce}_{2} \mathrm{O}_{3} @ \mathrm{Co}_{2} \mathrm{C}$ interface structures. In addition, strong correlations effects due to charge localization are modeled by adding a Hubbard U-like term to the PBE function. And the effect $\mathrm{U}$ value of $5.00 \mathrm{eV}$ for the $\mathrm{Ce} 4 \mathrm{f}$ states was applied. Spin polarization calculations were performed throughout the calculations. For the $\mathrm{Ce}_{2} \mathrm{O}_{3}$ cluster, the stoichiometric model was constructed from the corresponding bulk structure with the space group of $\mathrm{P} 3 \mathrm{~m} 1$.

Table S1. Elemental analysis of the different catalysts.

\begin{tabular}{ccccc}
\hline Sample & $\begin{array}{c}\text { Na concentrations } \\
(\text { wt. \% })^{b}\end{array}$ & $\mathrm{Co} / \mathrm{Ce}^{\mathrm{a}}$ & $\mathrm{Co} / \mathrm{Ce}^{\mathrm{b}}$ & $\begin{array}{c}\text { Ce concentrations } \\
(\text { wt. \% })^{\mathrm{b}}\end{array}$ \\
\hline $\mathrm{Co}_{3} \mathrm{O}_{4}$ & 1.4 & - & - & - \\
$\mathrm{CoCe} 192$ & 1.1 & 192 & 189 & 0.9 \\
$\mathrm{CoCe} 128$ & 1.2 & 128 & 111 & 1.5 \\
$\mathrm{CoCe} 64$ & 1.3 & 64 & 53 & 3.1 \\
$\mathrm{CoCe} 32$ & 1.3 & 32 & 30 & 5.3 \\
$\mathrm{CoCe} 16$ & 1.4 & 16 & 14 & 10.4 \\
\hline
\end{tabular}

${ }^{\mathrm{a}}$ Nominal loadings, ${ }^{\mathrm{b}}$ Measured with XRF 
Table S2. Reduction degrees of the different samples.

\begin{tabular}{cc}
\hline Sample & Reduction Degree (\%) \\
\hline $\mathrm{Co}_{3} \mathrm{O}_{4}$ & 96.4 \\
$\mathrm{CoCe} 192$ & 86.3 \\
$\mathrm{CoCe} 128$ & 77.9 \\
$\mathrm{CoCe} 64$ & 42.1 \\
$\mathrm{CoCe} 32$ & 34.7 \\
$\mathrm{CoCe} 16$ & 33.0 \\
\hline
\end{tabular}

Table S3. Particle size of the $\mathrm{Co}_{2} \mathrm{C}$ phase in the spent catalysts.

\begin{tabular}{ccccc}
\hline \multirow{2}{*}{ Sample } & \multicolumn{2}{c}{$\mathrm{d}_{\text {XRD }}(\mathrm{nm})$} & \multicolumn{3}{c}{$\mathrm{d}_{\text {TEM }}(\mathrm{nm})$} \\
\cline { 2 - 5 } & $(111)$ & $(021)$ & Mean diameter & Surface mean diameter \\
\hline $\mathrm{Co}_{3} \mathrm{O}_{4}$ & 33.1 & - & 75.7 & 108.3 \\
$\mathrm{CoCe} 192$ & 26.9 & - & 30.2 & 42.1 \\
$\mathrm{CoCe} 128$ & 24.4 & - & 25.4 & 38.4 \\
$\mathrm{CoCe} 64$ & - & 20.7 & 14.6 & 29.4 \\
$\mathrm{CoCe} 32$ & - & 17.5 & 13.2 & 26.7 \\
$\mathrm{CoCe} 16$ & - & 15.5 & 10.2 & 19.1 \\
\hline
\end{tabular}


Table S4. Catalytic performance of the $\mathrm{Co}_{3} \mathrm{O}_{4}$ and CoCe catalysts at $260{ }^{\circ} \mathrm{C}, 1 \mathrm{bar}, 3000 \mathrm{~mL} /(\mathrm{h} \mathrm{g}$ cat $)$, and $\mathrm{H}_{2} / \mathrm{CO}=2(\mathrm{v} / \mathrm{v})$.

\begin{tabular}{|c|c|c|c|c|c|c|c|c|c|c|c|c|c|}
\hline \multirow{2}{*}{ Catalyst } & \multirow{2}{*}{ CO Conv. $(\mathrm{C} \%)$} & \multirow{2}{*}{$\begin{array}{c}\mathrm{CTY}\left(10^{-6}\right. \\
\left.\mathrm{mol}_{\mathrm{CO}} /\left(\mathrm{g}_{\mathrm{Co} 2 \mathrm{C}} \cdot \mathrm{s}\right)\right)^{\mathrm{a}}\end{array}$} & \multirow{2}{*}{$\mathrm{CO}_{2}$ Sele. $(\mathrm{C} \%)$} & \multicolumn{6}{|c|}{ Product Selectivity $\left(\mathrm{C} \%, \mathrm{CO}_{2}\right.$-free $)$} & \multicolumn{4}{|c|}{ O/P Ratios } \\
\hline & & & & $\mathrm{CH}_{4}$ & $\mathrm{C}_{2}=$ & $\mathrm{C}_{3}=$ & $\mathrm{C}_{4}=$ & $\mathrm{C}_{2-4}=$ & $\mathrm{C}_{5+}+\mathrm{Oxy}$ & $\mathrm{C}_{2}$ & $\mathrm{C}_{3}$ & $\mathrm{C}_{4}$ & $\mathrm{C}_{2-4}$ \\
\hline $\mathrm{Co}_{3} \mathrm{O}_{4}$ & 1.9 & 0.3 & 38.6 & 16.1 & 15.6 & 11.9 & 5.3 & 32.8 & 48.2 & 13.2 & 12.4 & 7.8 & 11.6 \\
\hline CoCe192 & 6.9 & 1.0 & 43.5 & 15.4 & 14.9 & 14.6 & 6.6 & 36.0 & 45.9 & 13.0 & 15.5 & 10.3 & 13.2 \\
\hline CoCe128 & 10.3 & 1.6 & 38.3 & 9.8 & 11.1 & 16.4 & 7.3 & 34.7 & 53.7 & 15.2 & 25.8 & 16.9 & 19.4 \\
\hline СoCe64 & 21.8 & 3.9 & 42.3 & 7.4 & 9.8 & 23.3 & 11.0 & 44.2 & 46.6 & 13.8 & 34.5 & 22.4 & 23.5 \\
\hline $\mathrm{CoCe} 32$ & 22.3 & 4.8 & 45.0 & 6.4 & 9.6 & 24.6 & 11.8 & 45.9 & 46.0 & 16.6 & 39.6 & 25.7 & 27.7 \\
\hline $\mathrm{CoCe} 16$ & 10.9 & 2.8 & 43.8 & 7.4 & 9.8 & 20.5 & 9.5 & 39.8 & 51.3 & 17.5 & 35.4 & 22.9 & 25.6 \\
\hline
\end{tabular}

${ }^{\text {a }}$ Activity in terms of $\mathrm{CO}$ consumption. 

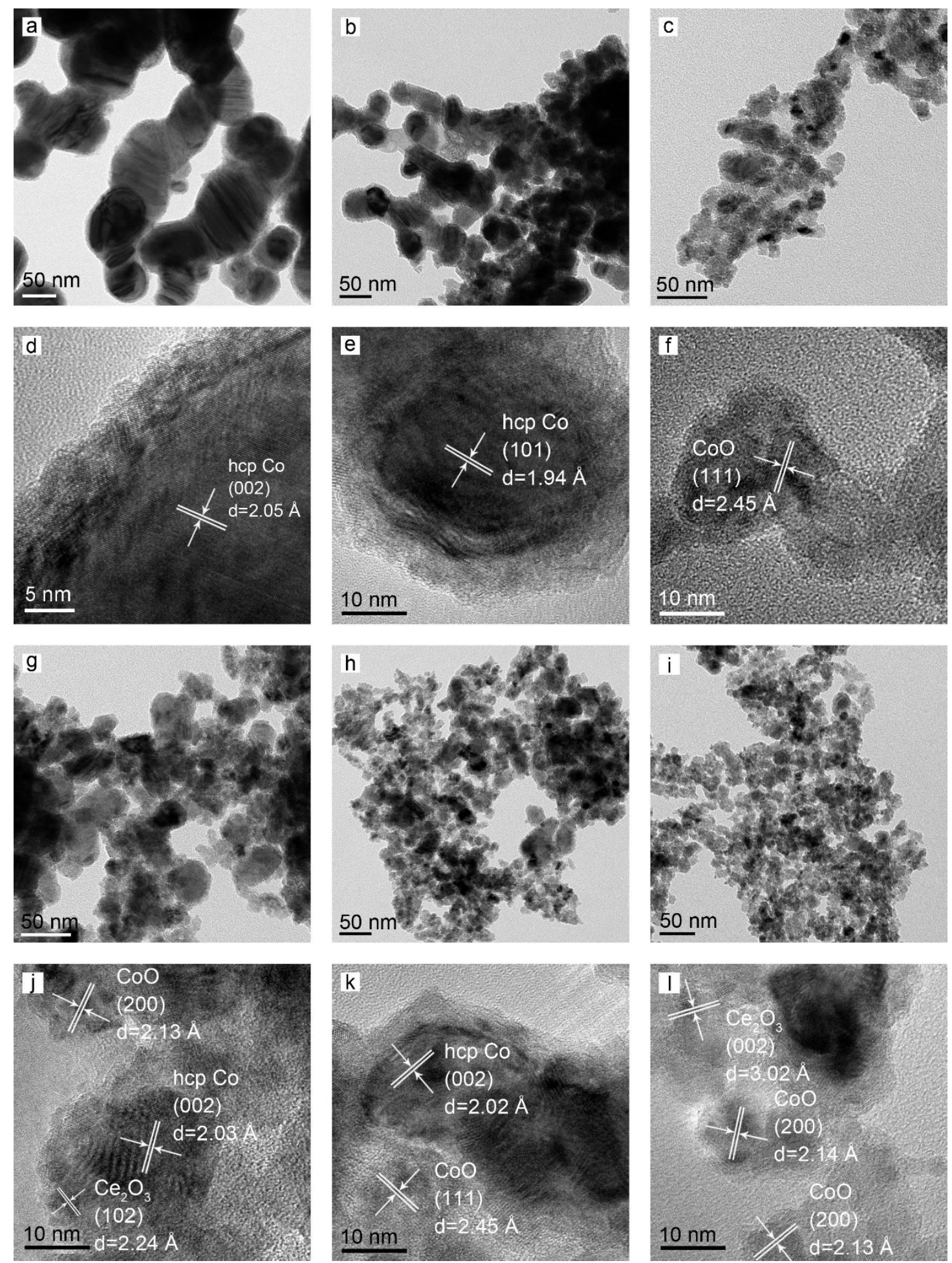

Figure S1. TEM images of the reduced catalysts: (a, d) $\mathrm{Co}_{3} \mathrm{O}_{4}$; (b, e) $\mathrm{CoCe} 192 ;(\mathrm{c}, \mathrm{f})$ CoCe128; (g, j) CoCe64; (h, k) CoCe32; (i, l) CoCe16. 

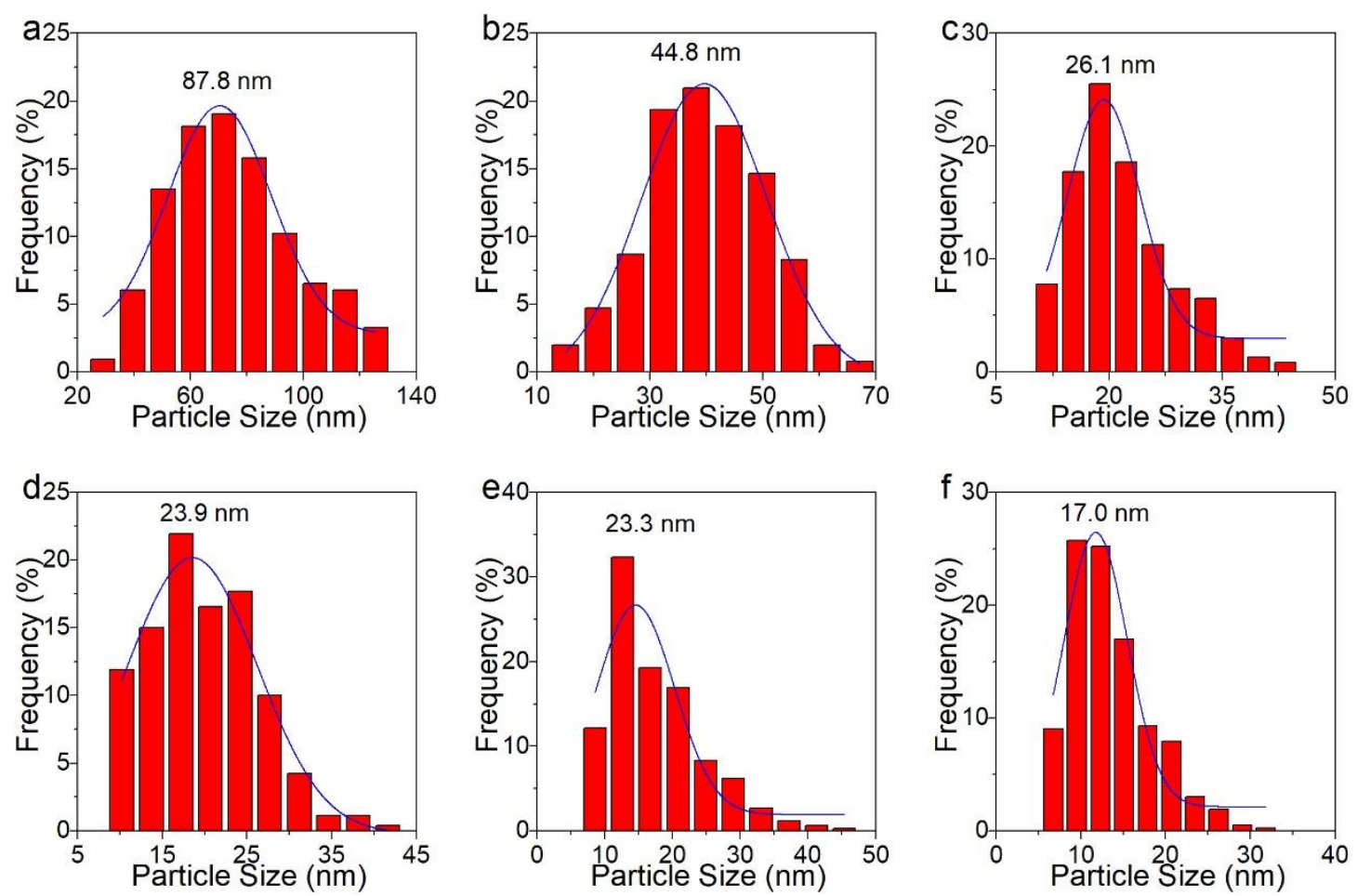

Figure S2. Particle size distributions of the reduced catalysts: (a) $\mathrm{Co}_{3} \mathrm{O}_{4}$; (b) CoCe192; (c) CoCe128; (d) CoCe64; (e) CoCe32; (f) CoCe16. 


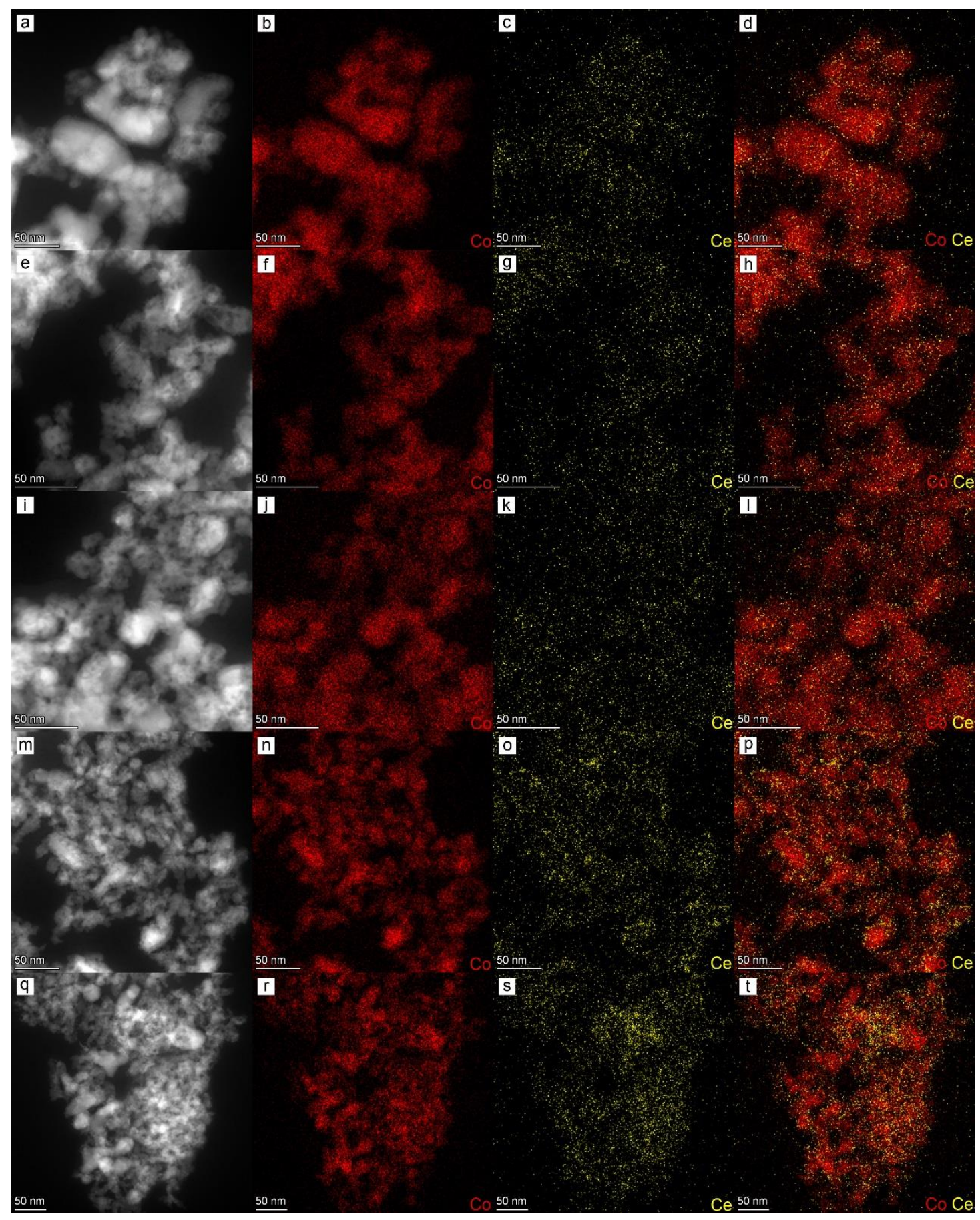

Figure S3. STEM-EDS images and elemental maps of the reduced catalysts: (a-d) CoCe192; (e-h) CoCe128; (i-1) CoCe64; (m-p) CoCe32; (q-t) CoCe16. The red and yellow dots were $\mathrm{Co}$ and $\mathrm{Ce}$ respectively. 

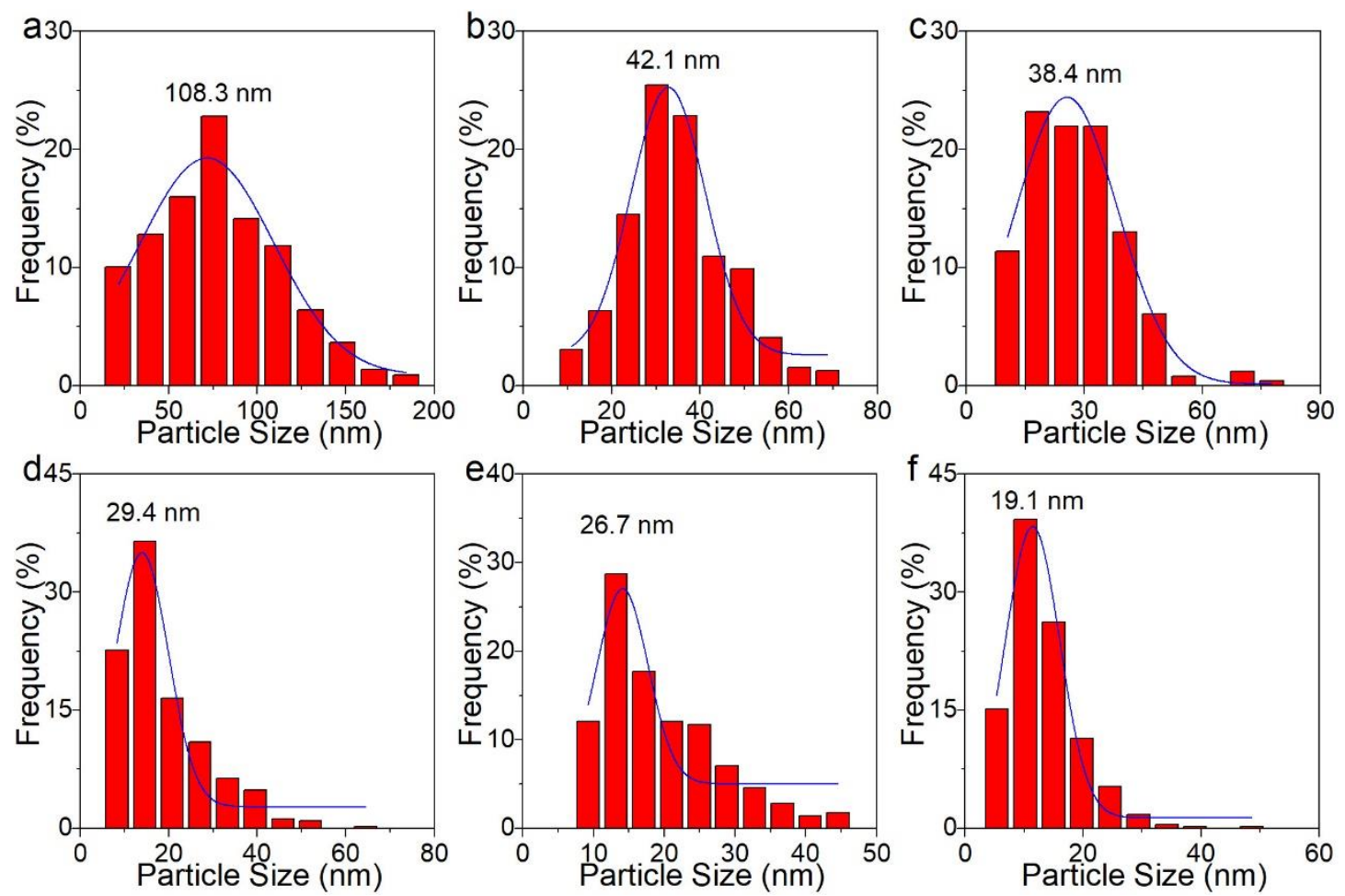

Figure S4. Particle size distributions of the spent catalysts in the shape of nanospheres: (a) $\mathrm{Co}_{3} \mathrm{O}_{4}$; (b) $\mathrm{CoCe} 192$; (c) $\mathrm{CoCe} 128$; (d) CoCe64; (e) CoCe32; (f) CoCe16. TOS $=45$ hours for the spent samples.

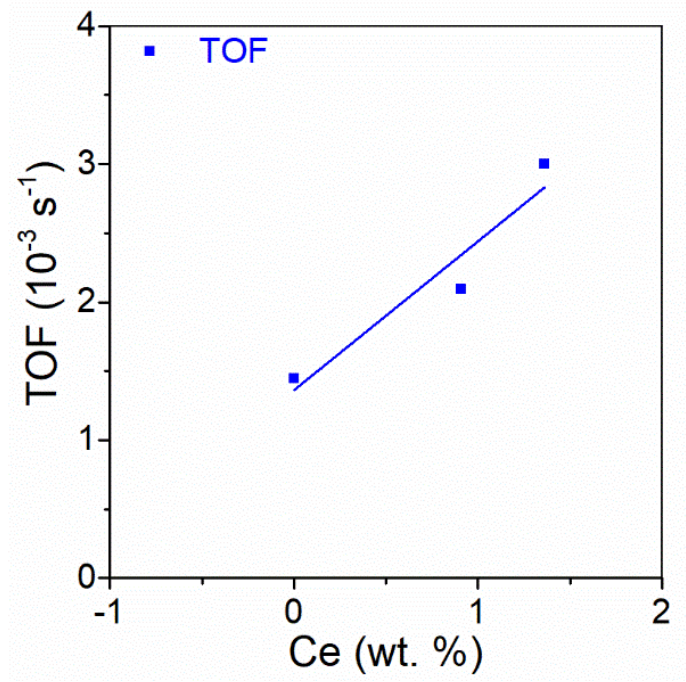

Figure S5. Turnover frequency of the $\mathrm{Co}_{3} \mathrm{O}_{4}, \mathrm{CoCe} 192$ and $\mathrm{CoCe} 128$ samples. 

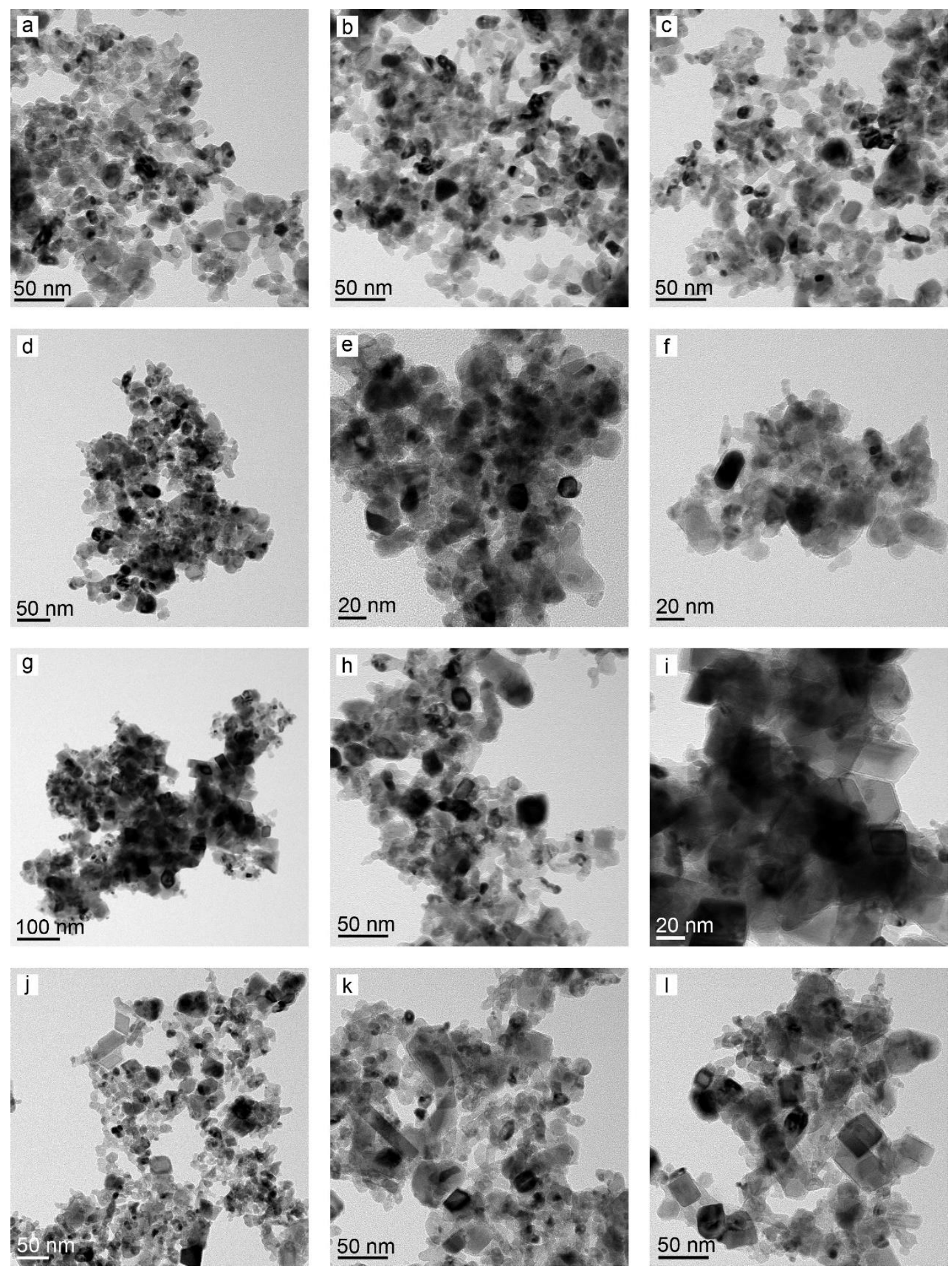

Figure S6. TEM images of the spent CoCe 32 catalysts with different TOS: (a-c) 5 h; (d-f) $10 \mathrm{~h}$; (g-i) $20 \mathrm{~h}$; (j-1) $30 \mathrm{~h}$. 

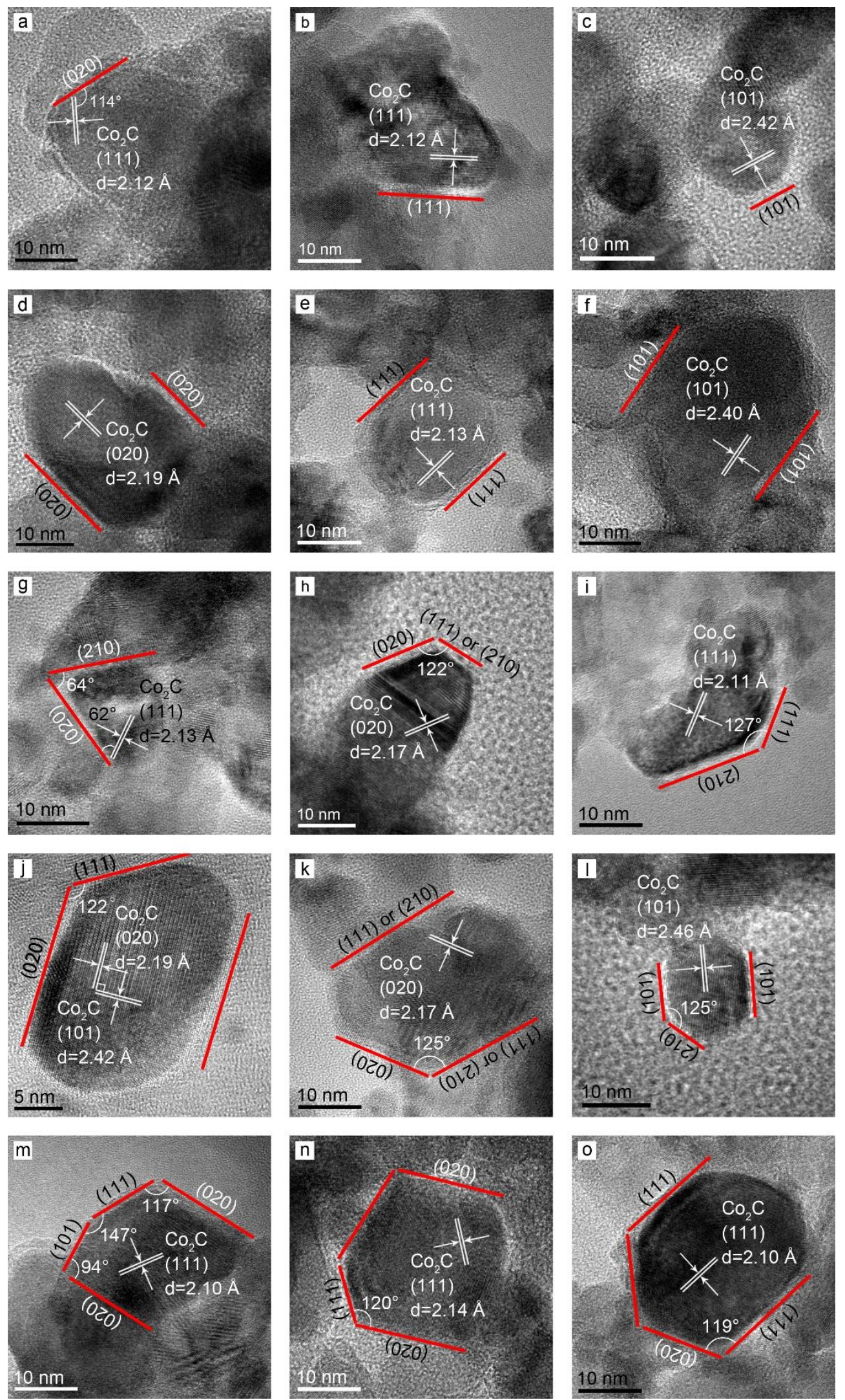

Figure S7. HRTEM images of the different intermediates: (a-c) intermediate b; (d-f) intermediate $\mathrm{c} ;(\mathrm{g}-\mathrm{i})$ intermediate $\mathrm{d} ;(\mathrm{j}-\mathrm{l})$ intermediate $\mathrm{e} ;(\mathrm{m}-\mathrm{o})$ intermediate $\mathrm{f}$. 

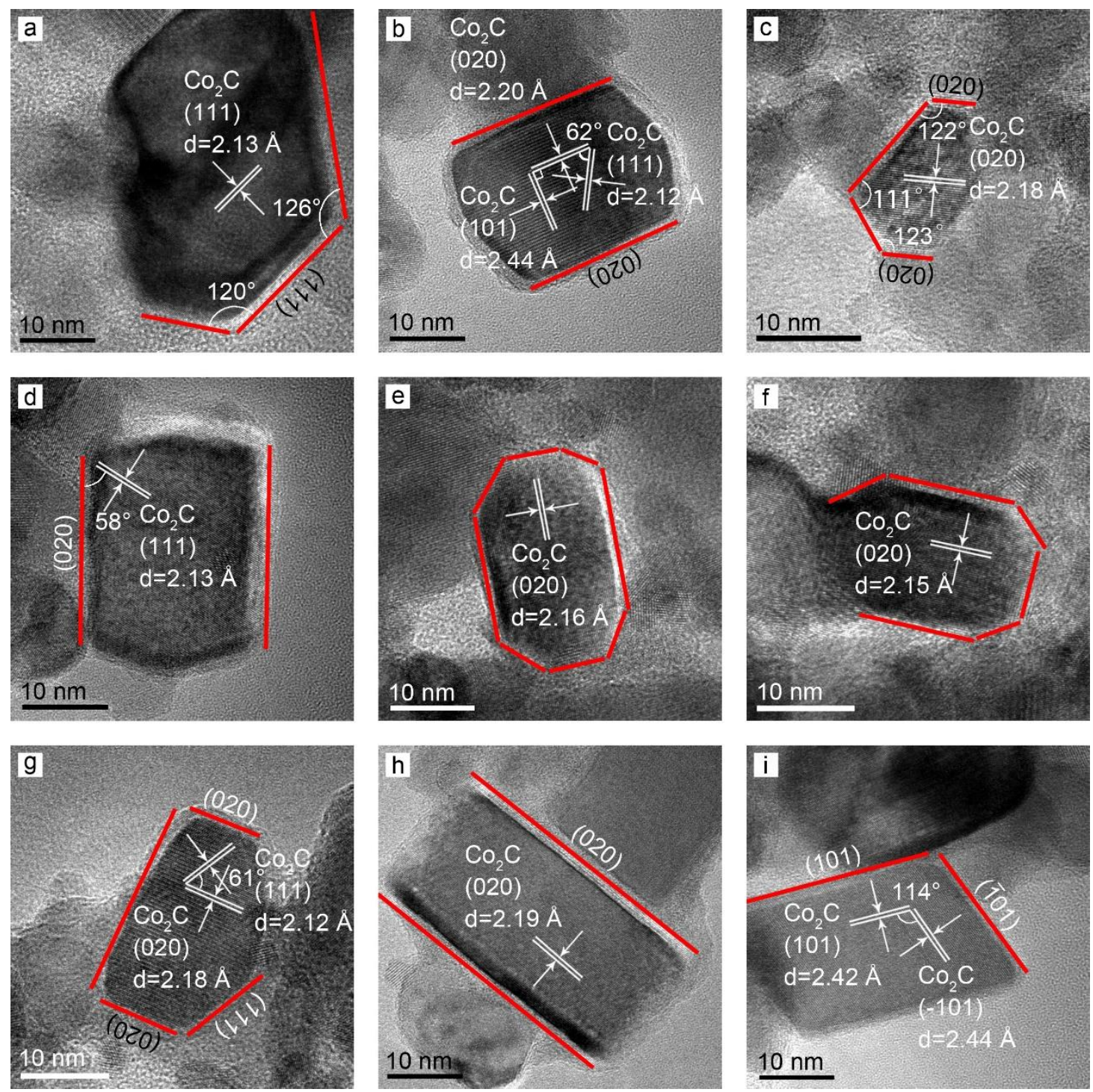

Figure S8. HRTEM images of the different intermediates and $\mathrm{Co}_{2} \mathrm{C}$ nanoprisms: (a-f) intermediate $\mathrm{g}$; $(\mathrm{g}, \mathrm{h})$ intermediate $\mathrm{h}$; (i) $\mathrm{Co}_{2} \mathrm{C}$ nanoprisms. 


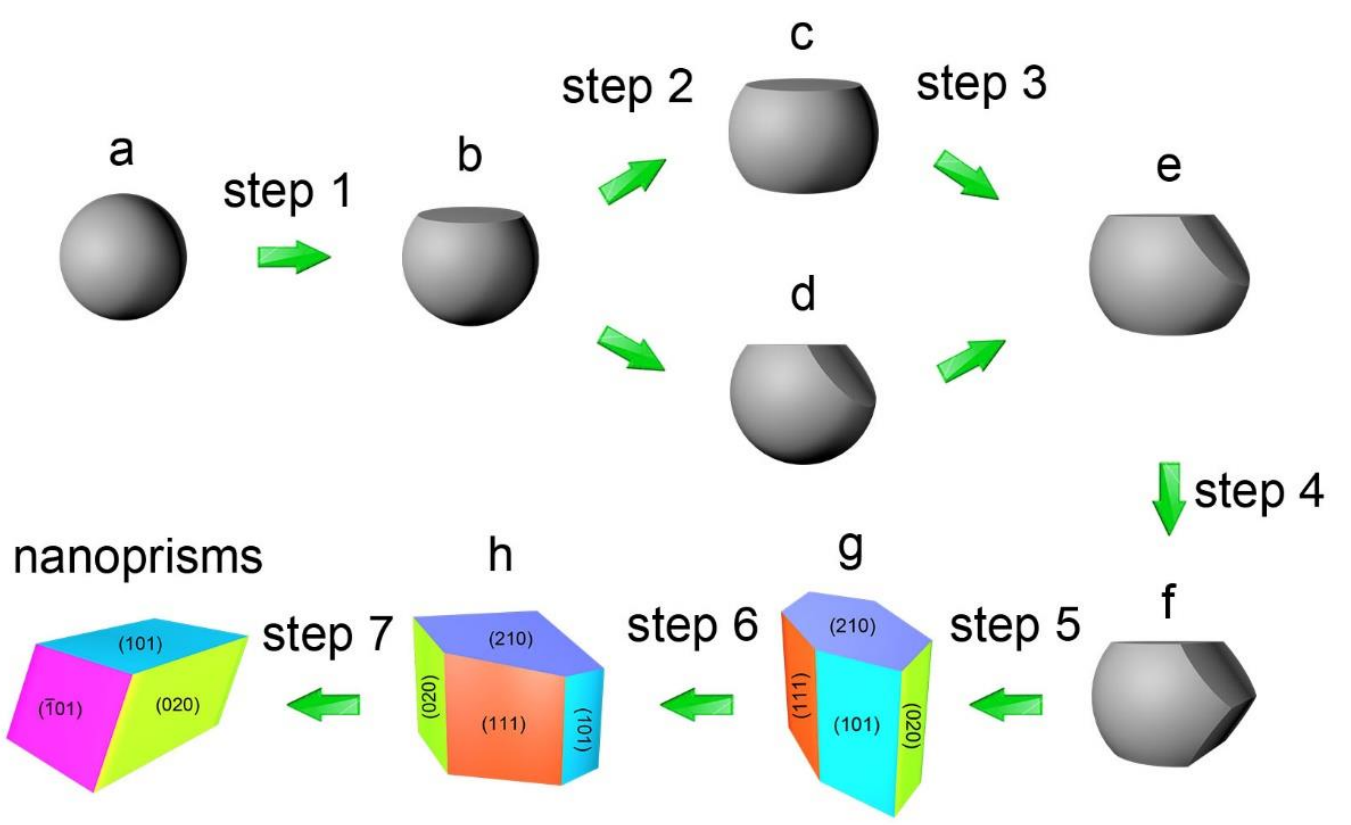

Figure S9. Sketch of the formation process of $\mathrm{Co}_{2} \mathrm{C}$ nanoprisms.
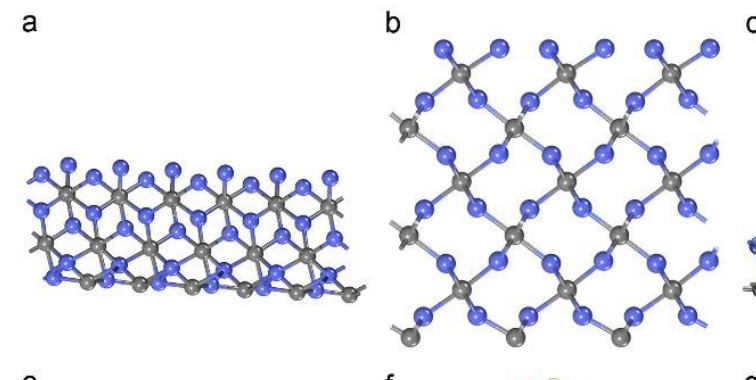

d

e
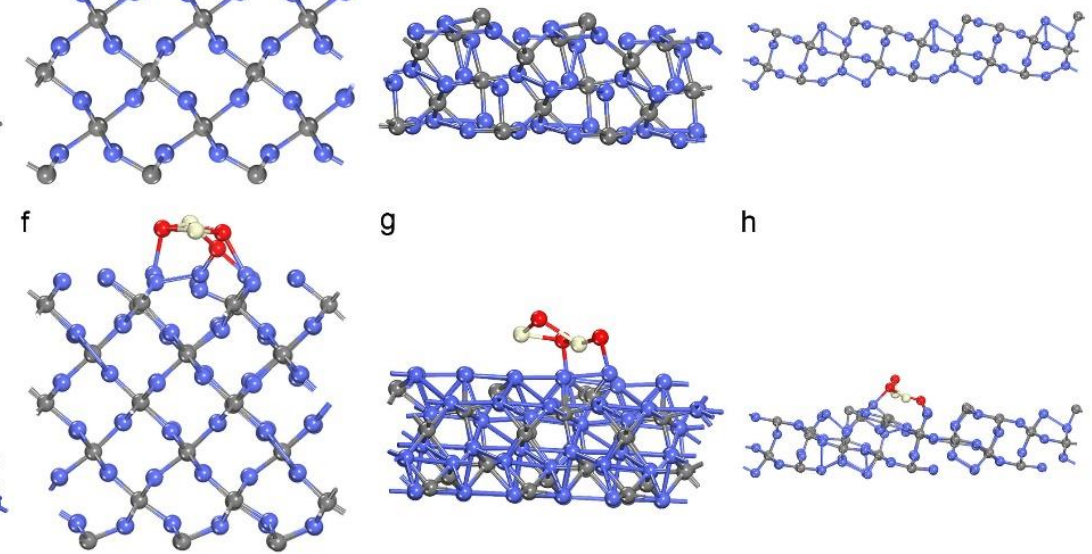

g

$\mathrm{h}$
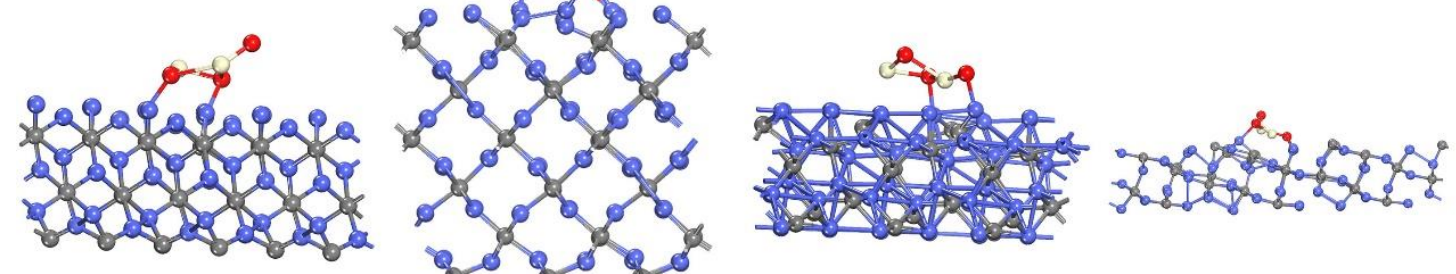

Figure S10. Side views of the clean surfaces and Ce-stabilized surfaces of the $\mathrm{Co}_{2} \mathrm{C}$ nanostructures: (a, e) (101); (b, f) (020); (c, g) (111); (d, h) (210). 